\title{
Parameters of visual simultaneity and of metacontrast and paracontrast of successively presented letters
}

\author{
PAUL FRAISSE \\ Sorbonne-Université de Paris*, Paris, France
}

Two stimuli of three consonants each were successively presented through a tachistoscope. Results show that the shorter the totel duration of $S_{1}+$ ISI $+\mathbf{S}_{2}$, the more of ten the two stimuli are perceived as simultaneous. For a given total duration, the perception of simultaneity depends on the ratio of durations $S_{1} / S_{2}$, according to a nonmonotonic function. The optimum is reached for a ratio higher than one. When the $S_{1} / S$, ratio increases from 0.25 to 4 , metacontrast decreases and paracontrast increases. These two phenomena are balanced for a value of the $S_{1} / S_{2}$ ratio which corresponds to the optimum of the perception of simultaneity.

The duration of the perceptual process is longer than that of the brief physiological stimulation which gives rise to it. This fact is illustrated by various phenomena, such as fusion, masking, apparent motion, refractory period, and short-term memory. It can also be revealed by means of different physiological techniques, particularly by the technique of the evoked potentials.

The duration of the perceptual process explains in particular the fact that successive stimulations may appear as simultaneous in conditions where visual perceptions are concerned. Simultaneity appears, for instance, when four dots arranged in the shape of a diamond are presented. The dots appear as simultaneous if the total duration between the lighting of the first and the fourth dot does not exceed $125 \mathrm{msec}$, variations in the temporal intervals between dots having no effect within these limits (Lichenstein, 1961). The threshold of simultaneity for the three borders (or the three angles) of a triangle is between 70 and $112 \mathrm{msec}$ (McFarland, 1965). The problem is particularly interesting in the case of letters (which form or do not form words). Hylan (1903) had noticed that six successively presented letters are perceived as simultaneous whatever the order of their presentation may be, provided the total duration does not exceed $80 \mathrm{msec}$. Stein (1928) has shown that the letters of a word, when flashed successively, in direct or in reverse order, are perceived in the same way as if they were presented simultaneously, provided that the total duration of successive flash does not exceed 100 msec.

With more modern techniques,

* Laboratoire associé au Centre National de la Recherche Scientifique, 28 , rue Serpente, 75-Paris- ${ }^{\circ}$, France.
Mayzner et al (1966 and 1967) have found that when presenting series of 5 or 10 letters forming words, there was perception of simultaneity if the total duration of presentation did not exceed 10 to $20 \mathrm{msec}$. If durations are a little longer, a variety of phenomena are observed, ranging from clear simultaneity to clear sequentiality. If letters are presented in the usual or in the reverse order, they are perceived with a very strong and a very rapid flow of movement from left to right or from right to left. If the letters are presented in random order, approximately the first half of these sequentially presented inputs are not perceived.

In a previous work (Fraisse, 1966), this problem of the perception of simultaneity was studied by presenting two successive sets of three letters, the letters of the second set being embedded in the ones of the first set. For instance, if $P$ T B form the first set and $N \mathrm{KX}$ the second one, in simultaneous presentation the whole set will form P N T K B X.

Such a technique has two advantages: (1) It does not give rise to any apparent movement, probably because the letters embedded are very close to each other and have not the same shape when successive pairs are considered. (2) It allows the study of the relationships between perception of simultaneity and effects of lateral masking. The number of letters to be perceived (six in all) is superior to the number of letters which can be perceived with brief exposures [ 3.5 letters are perceived in a presentation of $100 \mathrm{msec}$ (Fraisse \& Battro, 1960)]. The number of unperceived letters in the first set $\left(S_{1}\right)$ and in the second set $\left(S_{2}\right)$ provide, respertivoler indices of the metacontrast and paracontrast phenomena which can be studied in the same experimental situation.
This type of situation, in previous experiments, has led to the following results:

(1) The frequency of perception of simultaneity decreases with the increase of the total duration $T$ (Fraisse, 1966). $T=S_{1}+$ ISI $+S_{2}$, where $S_{1}=$ presentation duration of the first set of stimuli, $S_{2}=$ presentation duration of the second set of stimuli, and ISI = duration of the interstimulus interval. This result was obtained with two sets of three letters, each set forming a word and the whole set forming a word also; for example, $S_{1}=F E R$ (iron), $S_{2}=L U I$ (him), the whole set being F L E U R I (flowery). The durations of the stimuli $\left(S_{1}\right.$ and $\left.S_{2}\right)$ and of ISI were widely varied. It was found that the frequency of perception of simultaneity does not depend on the duration of any one of those indices or on the stimulus-onset asynchrony (SOA, Kahneman, 1968), but depends, rather, on their total duration. The threshold of perception of simultaneity at $50 \%$ is about $100 \mathrm{msec}$. The same result was found by Thor and Spitz (1968).

(2) Within the limits of a total duration of $100 \mathrm{msec}$, how ever, the relative durations of $S_{1}$ and $S_{2}$ play a role (Fraisse, 1968). It has been shown that the frequency of perception of simultaneity is dependent on the ratio of durations of $S_{1}$ and $S_{2}$, the maximum frequency corresponding to a value of $S_{1}$ higher than that of $S_{\text {. }}$. This result has been obtained with sets of consonants under several conditions.

(3) The frequency of perception of simultaneity decreases as the ISI durations increase when a constant total duration, $T$, and a constant $S_{1} / S_{2}$ ratio are used (Fraisse, 1968). This result was obtained with $T=100$ msec and $S_{1}=S_{2}$, ISI varying from 0 to $60 \mathrm{msec}$. From the comparison of these three effects, which were obtained in differing situations with different Ss and different materials, namely, words and consonants (Fraisse, 1968), it seems that the total duration, $T$, the duration of the $S_{1} / S_{2}$ ratio and of the interstimulus interval have a role of decreasing importance.

(4) Metacontrast and paracontrast, as estimated in the conditions of these experiments, evolve as follows: (a) When $S_{1}=S_{2}$, the curves have an inverted-U form, either for increasing values of $S_{1}$ and $S_{2}$ or for increasing values of ISI (Fraisse, 1966). (b) When one of the stimuli $\left(S_{1}\right.$ or $\left.S_{2}\right)$ is held constant and has a brief duration $(20 \mathrm{msec})$, the other being increased, metacontrast (or paracontrast) increases monotonically but paracontrast (increase in $S_{1}$ ) is far less 
Table 1

Presentation Durations of Stimuli (Msec) in the 24 Conditions

\begin{tabular}{|c|c|c|c|c|c|c|c|c|c|c|}
\hline \multirow[b]{3}{*}{$\mathrm{S}_{1} / \mathbf{S}_{2}$} & \multirow[b]{3}{*}{ I } & \multicolumn{9}{|c|}{$\begin{array}{r}\mathrm{T} \\
\mathrm{S}_{1}+\mathrm{I}+\mathrm{S}_{2} \\
\end{array}$} \\
\hline & & \multicolumn{3}{|c|}{60} & \multicolumn{3}{|c|}{90} & \multicolumn{3}{|c|}{145} \\
\hline & & $\mathbf{S}_{1}$ & & $\mathbf{S}_{2}$ & $\mathbf{S}_{1}$ & & $\mathbf{S}_{2}$ & $S_{1}$ & & $\mathbf{S}_{2}$ \\
\hline $1 / 4$ & $\begin{array}{r}0 \\
20\end{array}$ & $\begin{array}{r}12 \\
8\end{array}$ & : & $\begin{array}{l}48 \\
32\end{array}$ & $\begin{array}{l}18 \\
14\end{array}$ & : & $\begin{array}{l}72 \\
56\end{array}$ & $\begin{array}{l}29 \\
25\end{array}$ & $\begin{array}{l}: \\
:\end{array}$ & $\begin{array}{l}116 \\
100\end{array}$ \\
\hline $2 / 3$ & $\begin{array}{r}0 \\
20\end{array}$ & $\begin{array}{l}24 \\
16\end{array}$ & $\begin{array}{l}: \\
:\end{array}$ & $\begin{array}{l}36 \\
24\end{array}$ & $\begin{array}{l}36 \\
28\end{array}$ & : & $\begin{array}{l}54 \\
42\end{array}$ & $\begin{array}{l}58 \\
50\end{array}$ & $:$ & $\begin{array}{l}87 \\
75\end{array}$ \\
\hline $3 / 2$ & $\begin{array}{r}0 \\
20\end{array}$ & $\begin{array}{l}36 \\
24\end{array}$ & $\begin{array}{l}: \\
:\end{array}$ & $\begin{array}{l}24 \\
16\end{array}$ & $\begin{array}{l}54 \\
42\end{array}$ & : & $\begin{array}{l}36 \\
28\end{array}$ & $\begin{array}{l}87 \\
75\end{array}$ & $:$ & $\begin{array}{l}58 \\
50\end{array}$ \\
\hline 4 & $\begin{array}{r}0 \\
20\end{array}$ & $\begin{array}{l}48 \\
32\end{array}$ & : & $\begin{array}{r}12 \\
8\end{array}$ & $\begin{array}{l}72 \\
56\end{array}$ & : & $\begin{array}{l}18 \\
14\end{array}$ & $\begin{array}{l}116 \\
100\end{array}$ & $\begin{array}{l}: \\
:\end{array}$ & $\begin{array}{l}29 \\
25\end{array}$ \\
\hline
\end{tabular}

important than metacontrast (increase in $S_{2}$ ). (c) When the total duration, $T$, is held constant and is $100 \mathrm{msec}$, if the duration ratio $S_{1} / S_{2}$ is varied, metacontrast and paracontrast are equal for a $S_{1} / S_{2}$ ratio which corresponds to the maximum frequency of perception of simultaneity (Fraisse, 1968).

The two first results confirm classical results. Inverted-U curves "as a rule, are only obtained when the targets and masks are equal to each other in energy [Weisstein, 1968]."1 When the two stimuli are not equal in energy, monotonic curves are found Metacontrast increases with both increasing intensity (Alpern, 1953; Schiller, 1966) and duration of $S_{2}$ (the mask) (Alpern, 1953; Blanc-Garin, 1966, 1968) and complementarily with both decreasing luminance (Fehrer \& Smith, 1962) or duration of $S_{1}$ (the target) (Alpern, 1953; Schiller \& Smith, 1965; Blanc-Garin, 1966, 1968). Paracontrast increases with the duration of $S_{1}$ (Blanc-Garin, 1968).

Do metacontrast and paracontrast have equal effects on letter perception? Though Eriksen and Collins (1965) and Eriksen (1966) assumed these effects were symmetric, most authors, since Stigler (1910), have found that metacontrast was more important than paracontrast when duration and luminance of $S_{1}$ and $\mathrm{S}_{2}$ were equal (Alpern, 1953; Schiller \& Smith, 1965; Blanc-Garin, 1966, 1968).

Taking into consideration these results, one may hypothesize that when the $S_{1} / S_{2}$ ratio increases, metacontrast decreases and paracontrast increases, and that it will be possible to determine a value of this ratio for which the two effects of masking will be equivalent, using identical test and masking stimuli. It may also be assumed that this equality will hold with a $S_{1} / S_{2}$ ratio higher than one. That the value of this ratio, for which metacontrast and paracontrast are equivalent, is also the value for which perception of
At each presentation of two sets of three consonants, the $\mathrm{S}$ was asked (1) if the sets were successive or simultaneous (forced choice) and (2) to report the letters perceived. The $S$ was free to omit from recall the letters he had not identified. The number of false recognitions was nearly equal to zero. The criterion used in the present experiment was the number of correct responses.

\section{RESULTS}

Perception of Simultaneity

An analysis of variance performed on the 24 conditions showed that the total duration effect was significant at the .001 level, and that the $S_{1} / S_{2}$ ratio effect was significant at the .02 level. The effect of the interstimulus interval ( 0 or $20 \mathrm{msec}$ ) was in the predicted direction, but was not significant. Indeed, it was not possible, in the present experiment, to use a longer ISI since the smallest total duration was $60 \mathrm{msec}$. As the ISI had no significant effect, the data obtained when ISI was either 0 or $20 \mathrm{msec}$ have been combined for the analysis.

Figure 1 reveals results which support the hypotheses: (a) The frequency by which two sets of letters were perceived as simultaneous decreases as the total duration $S_{1}+$ ISI $+\mathrm{S}_{2}$ increases. (b) When the total duration is constant, the perception of simultaneity depends on the $S_{1} / S_{2}$ ratio. The relationship may be described by a function which reaches a maximum when $T$ is $60 \mathrm{msec}$, the $\mathrm{S}_{1} / \mathrm{S}_{2}$ ratio being 1.5 ; it corresponds to a slightly less marked maximum when $T$ is $90 \mathrm{msec}$, and to a monotonic curve when $\mathrm{T}=145 \mathrm{msec}$ but for this value the frequency of the perceived simultaneity is very low.

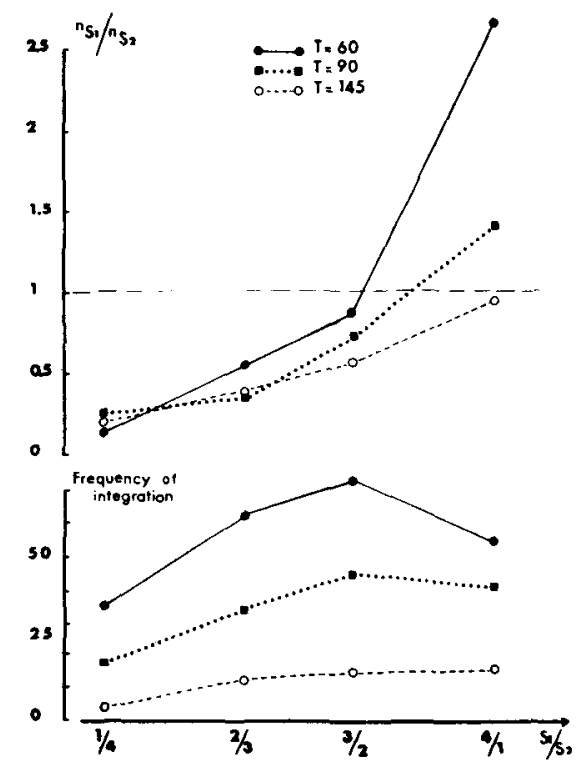

Figure 1. 

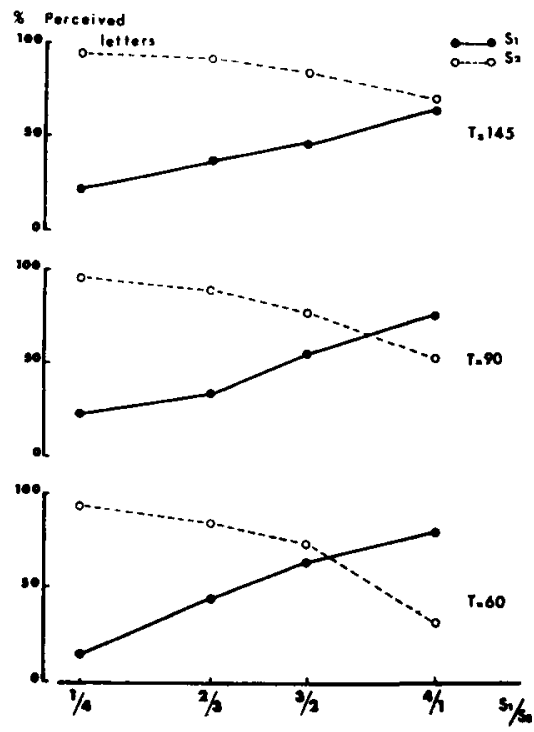

Figure 2.

\section{Metacontrast and Paracontrast}

In order to test the influence of all the independent variables, an analysis of variance was done, the dependent variable being the total number of perceived letters in each condition.

The analysis shows that the total duration, $T$, is not significant. Significance was obtained for the values of the $S_{1} / S_{2}$ ratio $(p<.001)$ and for ISI $(p<.05)$, the number of perceived letters being higher with ISI $=0$. However, as there was no significant interaction between ISI by $\mathrm{T}$ and ISI by $S_{1} / S_{2}$, the mean number of perceived letters with the two intervals was computed in order to simplify the presentation of the results.

The upper part of Fig. 1 shows a plot of the $\mathrm{nS}_{1} / \mathrm{nS}_{2}$ ratio $\left(\mathrm{nS}_{1}=\right.$ number of letters which have been perceived in the first set of stimuli; $\mathrm{nS}_{2}=$ number of letters which have been perceived in the second set of letters). $n S_{1} / n S_{2}$ increases for increasing values of $S_{1} / S_{2}$. When $S_{1} / S_{2}$ is less than one, metacontrast is superior to paracontrast. Then comes a value of $S_{1} / S_{2}$, where both maskings are balanced and after, when $S_{1}$ is much longer than $S_{2}$, paracontrast is superior to metacontrast.

The relative effect of masking is more evident in Fig. 2 where the percentages of letters perceived in $S_{1}$ and $S_{2}$, respectively, are plotted against the $S_{1} / S_{2}$ ratio.

Relationship between Perception of Simultaneity and Masking

The frequency of perceived simultaneity seems to be maximal when metacontrast and paracontrast are balanced $\left(\mathrm{nS}_{1} / \mathrm{nS}_{2}=1\right)$.

The values of $S_{1} / S_{2}$ for which the frequency of perceived simultaneity may be expected to reach an optimum have been computed by linear interpolation of the value of the ratio for $\mathrm{T}=60 \mathrm{msec}$ and $\mathrm{T}=90 \mathrm{msec}$ and by extrapolation for $T=145 \mathrm{msec}$. When $\mathrm{T}=60 \mathrm{msec}$, there would be an optimum with $S_{1} / S_{2}=1.67$; when $\mathrm{T}=90 \mathrm{msec}$, there would be an optimum with $\mathrm{S}_{1} / \mathrm{S}_{2}=2.47$; and when $T=145 \mathrm{msec}$ there would be an optimum with $S_{1} / S_{2}=4.71$.

This relation might contribute to an explanation of why the optimum of simultaneity did not appear in the present experiment with $T=145$ msec; indeed, the $S_{1} / S_{2}$ ratio to which this optimum would correspond was not included in the range of durations used in the present work.

Total Number of Perceived Letters

As the analysis of variance has shown, the total number of perceived letters remains approximately constant, whatever the total duration may be. The results are presented in Table 2.

\section{DISCUSSION AND CONCLUSIONS Simultaneity}

Frequency of perceptual simultaneity increases as total duration decreases. This is a common result. In addition, perception of simultaneity depends on the value of the $S_{1} / S_{2}$ ratio. It is easy to understand that when the difference in durations (and, consequently, in energy) of the two stimuli is too high, the $S$ disposes of supplementary cues for discriminating succession, e.g., the time lag between the onset of $S_{1}$ and of $S_{2}$ and between the offset of $S_{1}$ and of $S_{2}$. This last criterion has not been given enough attention in work on masking effects. To these differences in duration are also added differences in luminance. However, one can think that the duration of the stimuli has the main influence, since several authors (Kahneman, 1966, and principally Schurman, Eriksen, \& Rohrbaugh, 1968) have shown that the duration could have a specific role in the perception of forms, even within the temporal limits of integration ( $\mathrm{x}$ t) predicted by Bloch's law. This result would, however, have to be verified in an experiment where the relative intensity of $S_{1}$ and $S_{2}$ would vary, the stimuli having an equal duration.

In this experiment, ISI does not have a significant role, a result which is not at variance, in our opinion, with the results obtained in 1968 . In the present design, indeed, we could not give ISI a value greater than $20 \mathrm{msec}$ as we wanted to use supraliminal values of $S_{1}$ and $S_{2}$ and to have important ratios for the durations. However, the results show that the proportion of responses of
Table 2

Number of Perceived Letters

\begin{tabular}{rllll} 
& \multicolumn{5}{c}{$\mathrm{S}_{1} / \mathrm{S}_{2}$} \\
\cline { 2 - 5 } $\mathrm{T}$ & $1 / 4$ & $2 / 3$ & $3 / 2$ & $4 / 1$ \\
\hline 60 & 3.1 & 3.8 & 4.0 & 3.3 \\
90 & 3.5 & 3.7 & 4.0 & 3.8 \\
145 & 3.4 & 3.8 & 3.9 & 4.0 \\
\hline
\end{tabular}

simultaneity decreases slightly when ISI increases from 0 to $20 \mathrm{msec}$. The results obtained in the previous as well as in the present experiment permit the conclusion that perception of simultaneity depends on $T$, on the $S_{1} / S_{2}$ ratio, and on ISI, by order of decreasing importance.

\section{Metacontrast and Paracontrast}

With a set of six letters, all the letters are not perceived within the limits of the brief exposures used. There is, indeed, a limit of short-term memory storage, which also appears in our experiment. But, within this limit, the contribution of the two sets is quite different, because they mask each other reciprocally, and masking effects are more important as target and mask stimuli are equivalent in the above-mentioned respects. Metacontrast decreases with increasing values of the $S_{1} / S_{2}$ ratio. This increase corresponds to an increase of the duration of $S_{1}$ (the target) and in a decrease of $\mathrm{S}_{2}$ (the mask). It is noteworthy to point out that within the limits of durations which have been used, the increase of $S_{1}$ cannot alone explain that the proportion of letters perceived varies increasingly from 0.24 to 2.4 letters. It suffices to compare the number of letters perceived in $S_{1}$ with the absolute duration of $S_{1}$ in the different conditions to see that the main factor is the value of the $S_{1} / S_{2}$ ratio and not the absolute duration of $S_{1}$. For instance, when the duration of $S_{1}$ is $30 \mathrm{msec}\left(\mathrm{T}=90 ; \mathrm{S}_{1} / \mathrm{S}_{2}=2 / 3\right), 1.12$ letters are perceived, and when the duration of $S_{1}$ is $29 \mathrm{msec}(T=145$; $\left.S_{1} / S_{2}=1 / 4\right), 0.57$ letter is perceived; but when the ratios are considered, the following results are found: $S_{1} / S_{2}=$ $2 / 3\left(T=90 ; S_{1}=30\right), 1.12$ letters are perceived, and $S_{1} / S_{2}=2 / 3(T=145$; $S_{1}=29$ ), 1.02 letters are perceived. This is not the only example; it can be verified by comparing Tables 1 and 2 . It should be noted, however, that these tables do not correspond exactly, since the values given are the means computed with ISI $=0$ and $20 \mathrm{msec}$, a grouping which slightly modifies the durations of $S_{1}$ and $S_{2}$, but in a negligible way for our concern.

Therefore, the increase in the duration of $S_{1}$ does not explain the increase in the number of perceived 
letters when the $S_{1} / S_{2}$ ratio increases. One must take into account the masking influence of $\mathrm{S}_{2}$, which decreases with its relative duration. The effect is monotonic. Paracontrast is explained by the same reasoning. We observe, however, that metacontrast is stronger than paracontrast since, in this situation, the target and the mask are equivalent as equality of the effects is obtained only when $S_{1} / S_{2}>1$.

These results, obtained in a novel situation, cannot be taken into consideration to support either theory of metacontrast (cf. Weisstein, 1968).

\section{Simultaneity and Metacontrast}

It is found that the frequency of simultaneity is maximum for a $S_{1} / S_{2}$ duration when metacontrast and paracontrast are balanced, i.e., when the $S$ perceives an equal quantity of stimuli in the first and in the second set. The predominance of one set on the other, whether it is through the duration or the information given by the asynchrony between the onset or the offset of the stimuli, increases the cues of nonsimultaneity. All that diminishes the differentiation between the sets, on the contrary, increases the opportunity of perceiving simultaneity for brief durations.

\section{REFERENCES}

ALPERN, M. Metacontrast. Journal of the Optical Society of America, 1953, 43, 648-657.

BLANC-GARIN, J. Les relations temporelles dans le masquage latéral visuel. Année Psychologique, 1966, 66. 365-381.
B L A N C - G A R I N, J, L'interaction spatio-temporelle des données de la perception visuelle. Thèse de $3^{\mathrm{e}}$ cycle, Paris-Sorbonne, 1968 (unpublished).

ERIKSEN, C. W. Temporal luminence summation effects in backward and forward masking. Perception \& Psychophysics, 1966, 1, 87-92.

ERIKSEN, C. W., \& COLLINS, J. F. A reinterpretation of one form of backward and forward masking in visual perception. Journal of Experimental Psychology, $1965,70,343-351$

ERIKSEN, C. W., COLLINS, J. F., \& GREENSPON, $T$. $S$. An analysis of certain factors responsible for nonmonotonic backward masking functions. Journal of Experimental Psychology, 1967, 75, 500-507.

FEHRER, E., \& SMITH, M. Effects of luminance ratio on masking. Perceptual \& Motor Skills, 1962, 14, 243-253.

FRAISSE, P. Visual perceptive simultaneity and masking of letters successively presented. Perception \& Psychophysics, $1966,1,285-287$.

FRAISSE, P. L'intégration et le masquage de lettres présentées en succession rapide. Année Psychologique, 1968, 68, 321-345.

FRAISSE, P., \& BATTRO, A. M. L'évolution de la capacite d'appréhension en fonction du temps d'exposition. Année Psychologique, 1960, 60, 295-307. HYLAN, J. P. The distribution of attention. I. Psychological Review, 1903, 10 , 373-403.

KAHNEMAN, D. Time-intensity reciprocity under various conditions of adaptation and backward masking. Journal of Experimental Psychology, 1966, 71, 543-549.

KAHNEMAN, D. Method, findings and theory in studies of visual masking. Psychological Bulletin, 1968, 70 , 404-425.

LICHENSTEIN, M. Phenomenal simultaneity with irregular timing of components of the visual stimulus. Perceptual \& Motor Skills, 1961, 12. 47-60.

MAYZNER, M. S., TRESSELT, M. E., \& COHEN, A. Preliminary findings on some effects of very fast sequential input rates on perception. Psychonomic Science, $1966,6,513-514$.

MAYZNER, $M$ S TRESSELT M. E.. ADRIGNOLO, A. J., \& COHEN, A. Further preliminary findings on some effects of very fast sequential input rates on perception. Psychonomic Science, 1967, 7, 281-282.

M CFARLAND, J. H. Sequential part presentation: A method of studying visual form perception. British Journal of Psychology, 1965, 56, 439-446.

SCHILLER, P. H. Forward and backward masking as a function of relative overlap and intensity of test and masking stimuli. Perception \& Psychophysics. 1966, 1 . 161-164.

SCHILLER, P. H., \& SMITH, M. C. A comparison of forward and backward masking. Psychonomic Science, 1965, 3, 77-78.

SCHURMAN D. L ERIKSEN, C. W. \& ROHRBAUGH, J. Masking phenomena and time-intensity reciprocity for form. Journal of Experimental Psychology, $1968,78,310-317$.

S TEIN, W T a chistoskopische Untersuchungen über das Lesen. Archiv für die gesamte Psychologie, 1928, 64, 301-346.

STIGLER, R, Chronophotische Studien über den Umgebungskontrast. Pflügers Archiv Physiologie, 1910, 134, 365-435.

THOR D H \& SPITZ H H Temporal discrimination as a function of total presentation time. Psychonomic Science, 1968, 13, 291-292.

WEISSTEIN, N. A Rashevsky-Landahl neural set: Simulation of metacontrast. Psychological Review, 1968, 75, 494-521.

\section{NOTE}

1. However, Eriksen, Collins, and Greenspon (1967) have found only monotonic functions when the target and the mask have equal durations and intensities. It should be noted that their experiment involved a task of localization.

(Accepted for publication February 15 1971.) 